\title{
Research on the Characteristics of Monitoring Data of Zipingpu High Gas Tunnel: Analysis and Prediction
}

\author{
Xiaobing Kang ${ }^{1,}$, , Sheng $\mathrm{Luo}^{2}$, Xiaoyun $\mathrm{Ma}^{1}, \mathrm{Mo} \mathrm{Xu}^{1}$, Leilei Guo ${ }^{1}$, Xiaodi $\mathrm{Shi}^{1}$, Zeyuan $\mathrm{Sun}^{2}$ \\ ${ }^{1}$ State Key Laboratory of Geohazard Prevention and Geoenvironment Protection, Chengdu University of Technology, \\ Chengdu, PR China 610059 \\ ${ }^{2}$ College of Engineering, Sichuan Normal University, Chengdu, PR China 610071
}

\begin{abstract}
The Zipingpu tunnel is a high gas tunnel, located in the expressway section of national highway 317 from Dujiangyan to Wenchuan in Sichuan province. During its construction, gas explosion occurred many times, including a serious explosion. On the basis of summarizing the existing gas tunnel construction experiences, the Zipingpu tunnel adopted a "double insurance" scheme, which combined automatic monitoring with manual test to build a real-time and continuous gas concentration monitoring system in the tunnel. By analyzing a large number of monitoring data, it is concluded that the main factors which affect the gas concentration are tunneling blasting, ventilation condition and geological structure. Furthermore, the classification and prediction model of gas monitoring data are proposed. The predicted results obtained from the model are consistent with the measured data. This work can provide reference for other gas tunnel projects.
\end{abstract}

Keywords: gas tunnel, dynamic monitoring, data analysis, fuzzy recognition, prediction model

\section{Introduction}

In recent years, with the implementation of China's Western Development Strategy, there is an increasing gas tunnels. Gas disaster has become one of the main geological hazards in tunnel construction (Tang et al 2003, Kang and Xu 2011, Cao and Wang 2013, Chang et al 2013, Gan 2014, Yuan 2014).

The occurrence of gas disaster can be eliminated based on a full understanding of influencing factors of gas disaster, together with the existing technologies (Kang and Xu 2011, Kang et al 2013, 2017). With the knowledge of accurate geological environment conditions on the tunnel site, effective measures can be taken before a potential danger through timely obtaining the information of gas concentration. If there is a discontinuity in monitoring time and important monitoring locations are missing, it is likely to cause serious consequence (Doyle 1976, 2001).

Therefore, it is necessary to build a comprehensive and real-time network monitoring system in the gas tunnel construction. Using this system, the effective gas accident prediction and early warning information would be extracted from monitoring.

\section{General Situation}

The Zipingpu tunnel is located in national highway 317 from Dujiangyan to Wenchuan in Sichuan province, China. The construction of this tunnel is a difficult project. It is a high gas tunnel, designed for double tunnels. The left one is
4,090 $\mathrm{m}$ long, the right is $4,060 \mathrm{~m}$ long, and its maximum depth exceeds $550 \mathrm{~m}$. Abnormal gas emission repeatedly occurred during the construction. In the preliminary geological survey, it was estimated that the gas emission is less than $0.5 \mathrm{~m}^{3} / \mathrm{min}$ when the tunnel passes through the coal seam and coal strata. According to the "railway gas tunnel technical specification" (TB10120-2002), this tunnel belongs to a low gas tunnel. However, a gas explosion occurred in the tunnel construction at $2 \mathrm{pm}$ on December 22, 2005. The measured absolute gas emission was 3.19 $\mathrm{m}^{3} / \mathrm{min}$ at tunnel face. It proves that this tunnel is actually a high gas tunnel.

The tunnel area lies in the northwestern Sichuan basin. It features with a higher elevation in northwest and a lower elevation in southeast. The depth difference between them ranges from $1,000 \mathrm{~m}$ to $3,000 \mathrm{~m}$. The upper Triassic Xujiahe group $\left(\mathrm{T}_{3} \mathrm{xj}\right)$, is the main stratum which the tunnel passes through. According to the lithology combination features of the stratum, it can be divided into three sections. The first section is not in the tunnel area. The tunnel mainly passes through the second section $\left(\mathrm{T}_{3} \mathrm{xj}^{2}\right)$, which contains fifteen lithologic layers. The odd layer is mainly composed of mudstone, intercalated with siltstone or carbonaceous mudstone and coal line; the even layer comprises sandstone or siltstone which is mixed with mudstone. The third section $\left(\mathrm{T}_{3} \mathrm{xj}^{3}\right)$ is only exposed in lower stratum of the footwall of the fault, which is composed of yellow-gray and brownish-yellow thick layered coarse sandstone, fine

* Corresponding Author: Xiaobing Kang, Email: kangxiaobing09@cdut.cn, phone: +(86) 28-8407-3193 
conglomerate, muddy siltstone, with a small amount of carbonaceous mudstone in middle.

The coal seam in the tunnel area is bituminous coal with middle-high metamorphism degree, however its thickness is small and the reserves are very few. The tunnel passes through coal seam and carbon mudstone mostly by a large angle, and the total amount of released gas is limited. The geological structure in the area is complex, and the fault fold and the joints and fissures in the rock strata are developed, which result in the poor conditions of gas seal. The above features cause the poor occurrence condition of coal seam gas formation. However, the tunnel is deep buried, there may be a gas accumulation in some local areas. Thus, coal seam gas hazard still exists.

\section{Gas Monitoring System}

\subsection{Monitoring methods and means}

Due to the possible gas accumulation, the automated monitoring and manual test method have been used in Zipingpu, and a networked, real-time monitoring system has been built to continuously monitor gas concentration in the tunnel (Fig. 1).

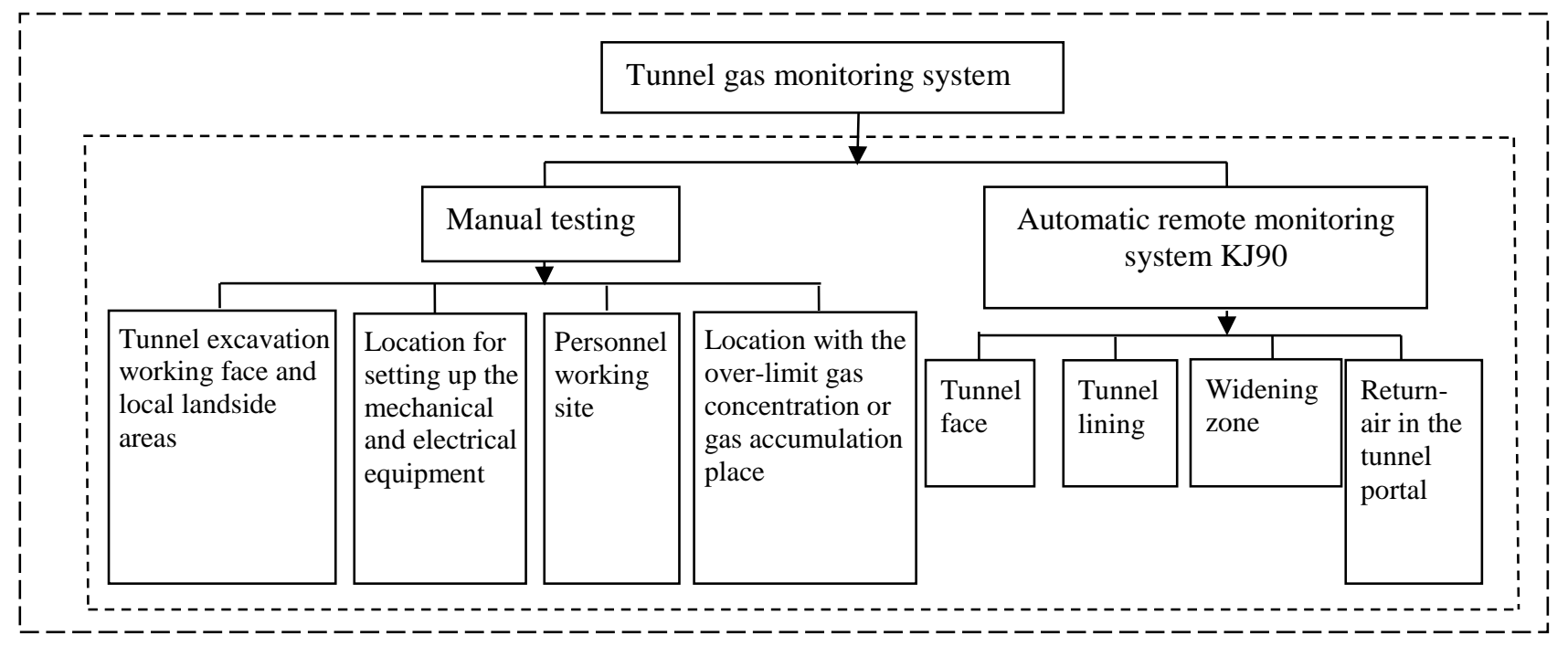

Fig. 1 The comprehensive real-time monitoring system

Table 1 Automatic monitoring sensor arrangement and number in tunnel (single opening)

\begin{tabular}{cccc}
\hline Location & Sensor type & Number(set) & Function \\
\hline \multirow{2}{*}{ Excavation surface } & KG9701 & 1 & Testing methane concentration in working face \\
\cline { 2 - 4 } & GY25 & 1 & Testing oxygen concentration in working place \\
\hline Second lining work-place & KG9701 & 1 & Testing methane concentration \\
\hline Widening zone & KG9701 & 1 & Testing methane concentration \\
\hline Return-air & KG9701 & 1 & Testing methane concentration \\
\hline Outside the tunnel & KTC-90 & 1 & Testing on/off status of fan \\
\hline
\end{tabular}

KJ90 remote automatic monitoring system developed by Chongqing Coal Science Research Institute is employed for real-time monitoring in all important locations. This can greatly avoid leaking problem (Zhong 2006, Su et al 2011). If the gas concentration exceeds the standard value, abnormal data can be immediately detected by the surveillance system, and once the gas concentration reaches $1 \%$, the power is immediately off. KJ90 system is composed of a computer, a printer, data communication interface, substation, communication cable and a sensor. Eight-module substation KFD-2 is used and it can control eight switches. KG9701 low concentration gas detectors were set up in the excavation face, second lining trolley, widening zone and return-air in the tunnel portal (Table 1).

In addition to the automatic monitoring system, the light interference gas detector is used to detect the gas manually. Portable gas detector combines alarm instrument with power-off instrument which detects gas concentration continuously and automatically. When the gas concentration is higher than the standard value, the power supply will be cut off. Each inspection staff is equipped with a light interference gas detector.

Gas detection locations contain: excavation face, horizontal channel, lining trolley, waterproof board, local fan and switch, mechanical and electrical equipment in the return-air, areas within $20 \mathrm{~m}$ in blasting sites, as well as special inspection sites, such as burning welding places, other personnel working places etc. Three or five positions are inspected in arch test location, including the top, both sides of the arch feet and the corners. 


\subsection{Monitoring requirements}

Gas concentration is the main factor threatening gas tunnel safety. The biggest characteristic of the "double insurance" gas monitoring system is to carry out a comprehensive, real-time monitoring of the entire tunnel. Once the gas concentration is over limit, immediate measures will be taken (Hu 2012). The limit value of gas concentration and treatment measures in different locations inside the tunnel are shown in Table 2 (Technical Code for Railway Tunnel with Gas (TB10120-2002) 2002, National Coal Mine Safety Supervision Bureau 2005).

Table 2 Gas concentration limit and treatment measures in the tunnel

\begin{tabular}{|c|c|c|c|}
\hline No. & Site & Limit & Treatment measures \\
\hline 1 & Any position in the low gas area & $0.5 \%$ & $\begin{array}{l}\text { Stop work immediately in the area within } 20 \text { m near } \\
\text { the position where gas concentration is over limit, } \\
\text { find out the reason, enhance ventilation }\end{array}$ \\
\hline 2 & $\begin{array}{l}\text { Area with Local gas accumulation (Volume is } \\
\text { more than } 0.5 \mathrm{~m}^{3} \text { ) }\end{array}$ & $2.0 \%$ & $\begin{array}{l}\text { Stop work immediately in the area within } 20 \text { m near } \\
\text { the position where gas concentration is over limit, } \\
\text { power off, evacuation, treatment, enhance ventilation }\end{array}$ \\
\hline \multirow[b]{2}{*}{3} & \multirow[b]{2}{*}{ Airflow of the excavation work face } & $1.0 \%$ & Stop drilling \\
\hline & & $1.5 \%$ & $\begin{array}{l}\text { Stop work, evacuation, power off, identify the cause, } \\
\text { enhance ventilation etc. }\end{array}$ \\
\hline 4 & Return-air way or airflow of workface & $1.0 \%$ & Stop work, evacuation, treatment \\
\hline 5 & $\begin{array}{l}\text { Airflow in the area within } 20 \mathrm{~m} \text { near the blasting } \\
\text { sites }\end{array}$ & $1.0 \%$ & Prohibit blasting \\
\hline 6 & Airflow in workface after blasting & $1.0 \%$ & Continue to ventilate, prohibit entry \\
\hline 7 & $\begin{array}{l}\text { Area within } 10 \mathrm{~m} \text { near the local fan and electric } \\
\text { switch }\end{array}$ & $0.5 \%$ & Stop work, evacuation, treatment \\
\hline 8 & Area within $20 \mathrm{~m}$ near the Motor and the switch & $1.5 \%$ & Stop work, evacuation, power off, treatment \\
\hline 9 & Anywhere in the tunnel after completion & $0.5 \%$ & Identification of leakage points, remediation \\
\hline
\end{tabular}

\section{Analysis on Characteristics of Monitoring Data}

\subsection{Characteristics of monitoring data}

After the explosion accident, a comprehensive and realtime system was used to monitor the gas concentration in different locations of the tunnel, and a lot of data was obtained. Through statistical analysis of a large amount of data and combination with data characteristics from the existing engineering examples (Liu and Zhao 2007), the tunnel gas monitoring data can be divided into the following three types according to the shape of the data itself and its changing trend (Liu and Xing 1999) (Table 3).

\subsection{Environmental factors affecting gas monitoring data of tunnel}

Besides its own geological background factors, there are also a lot of external environmental factors that lead to abnormal monitoring data, and then the occurrence of the gas accident in the tunnel.

\subsubsection{Influence of blasting}

In the construction process of blasting and driving there are two aspects of the influence on gas emission: 1) Pressure relief and gas release. The stress concentration zone ahead of the working face moves to the coal body, which ensures the width of the relief zone and safe driving; 2) In the coal seam subjected to vibration under blasting, the stress equilibrium state and the high gas gradient are changed in front of the working face, which is beneficial to the gas emission.

The gas concentration statistics data before and after blasting at the Zipingpu tunnel exit is shown in Fig. 2 (from November 2017 to December 2007). Obviously, the concentration of gas after blasting is often much higher than before. Blasting changes the connectivity of gas emission path in the surrounding rock, which is conducive to the gas emission.

\subsubsection{Influence of different sampling environments}

Feature and environmental factors of gas explosion accidents from 1980 to 2000 are analyzed and compared. The probability of the occurrence of gas explosion is different due to different environmental characteristics. Environmental characteristics are the sampling environments mentioned in this paper. The sampling environments face, lining, broadband and return-air. Gas emission in different sampling environments has different characteristic (Fig. 3).

The following three characteristics are obtained from the classification statistics from the concentration data of four monitoring locations: 1) Abnormal times in the face and lining are obviously more than that in the widening zone and return air; 2) Delay ratio in the face and lining is significantly lower than widening zone and return air; and 3) The occurrence frequency of triangle type for the Zipingpu tunnel monitoring data is obviously higher than multi-peak and increment types. 
Table 3 Tunnel gas monitoring data classification

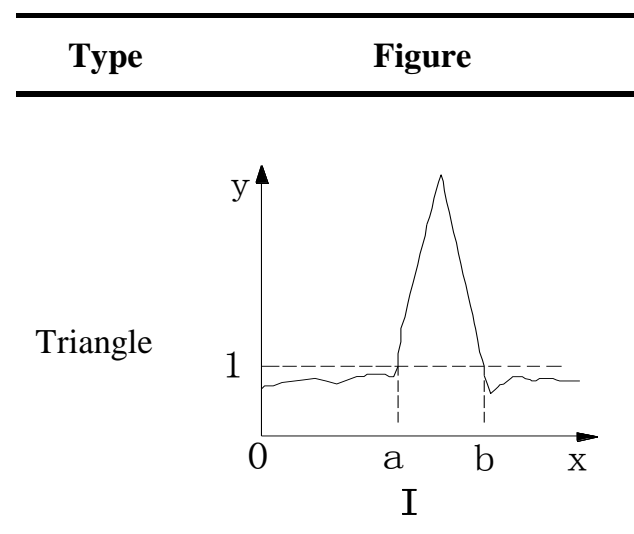

\section{Characteristics description}

Normally in a stable state. A certain excitation (such as blasting, drilling, etc.) causes a substantial change of gas concentration within a short period of time, sometimes the concentration exceeds the warning value. As the gas reserves are very few, the concentration will soon be back to a stable state, and we deem that the state is normal.
Actual monitoring curve

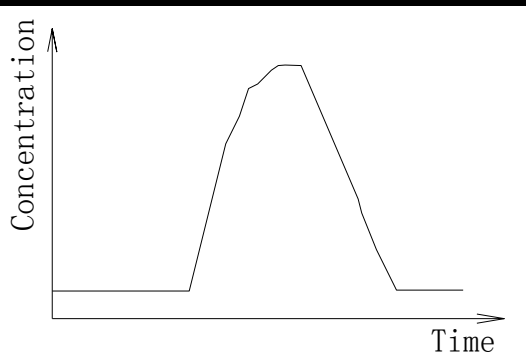

The gas concentration curve of widening division from 6:00 am to 9:00 am on Nov 20, 2007.

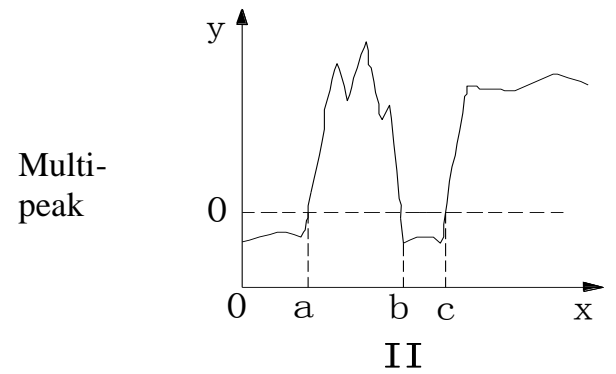

A special type of curve. The abnormal gas concentration is caused by multiple factors. The oscillation at the top curve occurs and a number of peaks form. Abnormal gas emission is likely to occur in a period of time after the appearance of this feature

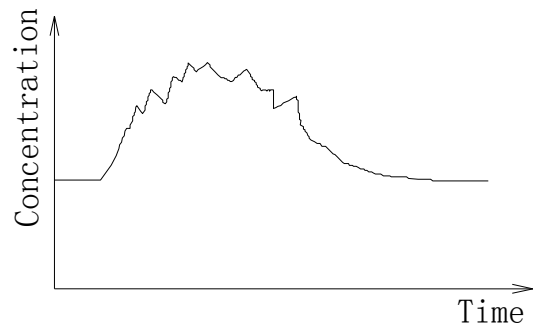

The gas concentration curve of tunnel lining from 6:00 pm to 9:00 pm on Nov. 24, 2007.

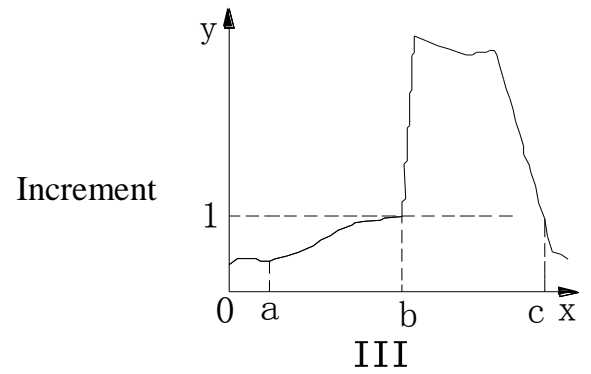

Another special type of curve. The abnormal gas concentration is caused by multiple factors. As shown in Figure c, the slope is low in the starting stage from a to $b$, and rises suddenly after $b$, and then falls to normal value after a long period of time.

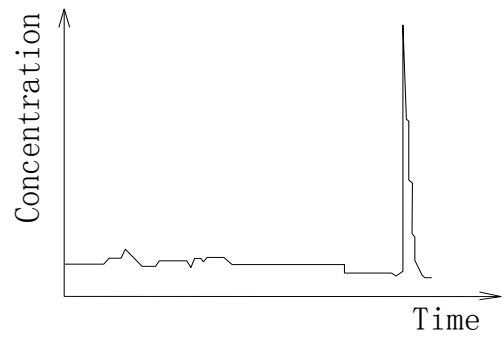

The gas concentration curve of tunnel lining from 10:00 am on Dec 5, 2007 to

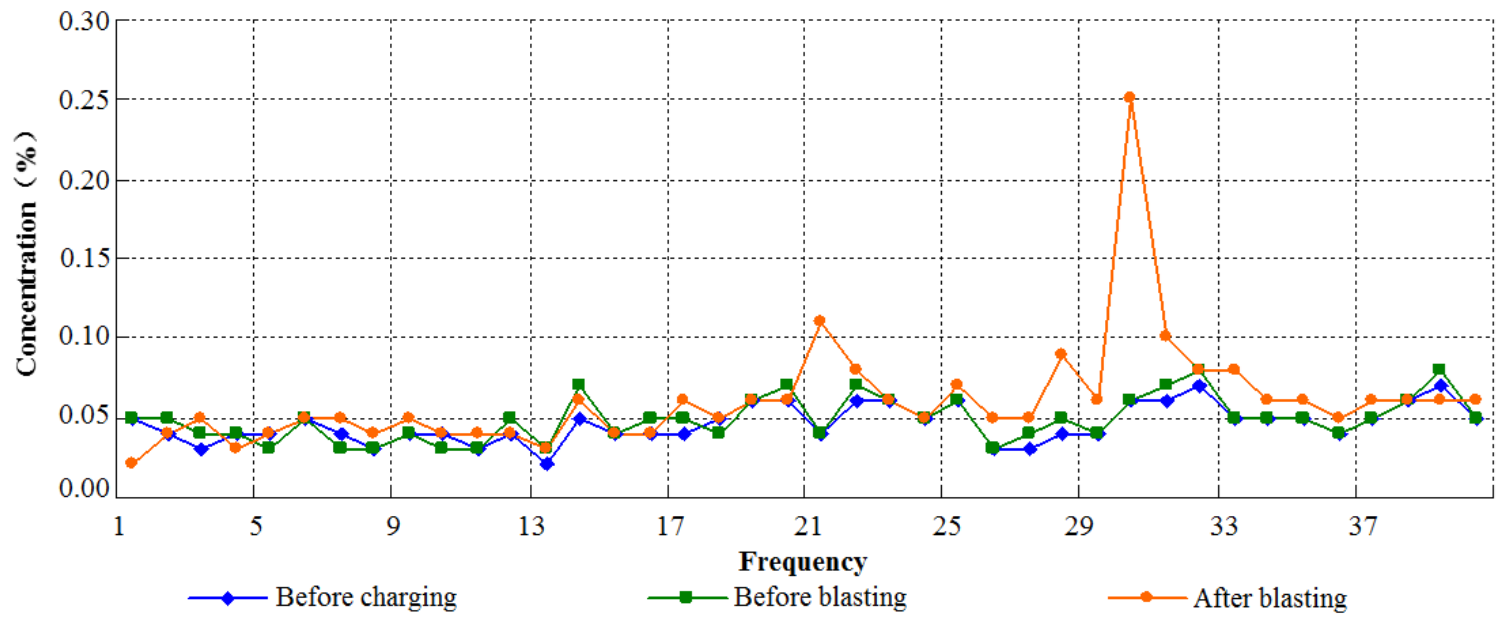

Fig. 2 Gas concentration statistics data before and after 41 blasts at the Zipingpu tunnel export 


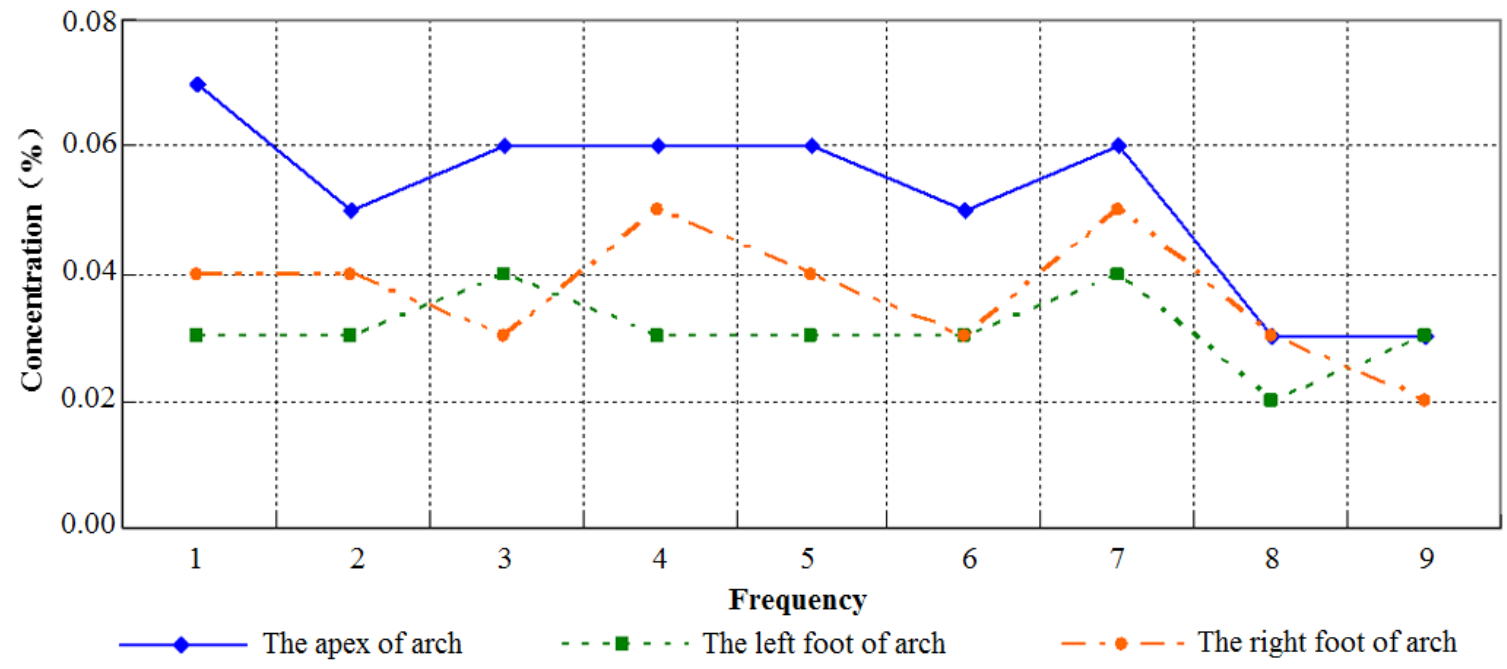

Fig. 3 Variation curve of gas concentration at the tunnel face in the place K16+578 (K16+578 represents $16.578 \mathrm{~km}$, the distance of the measurement location from the starting point of the highway)

\subsubsection{Influence of different geological background}

During June 11, 2006 to November 1, 2007, there were a total of 156 times gas over-limit, 24 in segment K17 of the right tunnel, 13 in segment K16 of the left tunnel, and 119 in the segment K16 of the right tunnel.
Combined with the geological background, the segment analysis for 119 times gas over-limit was performed at K16 in the right tunnel. From the sketch of the face, it can be seen there is a greater possibility of gas overlimit for the more complex structure (Table 4).

Table 4 The segment analysis at K16 in the right tunnel

\begin{tabular}{|c|c|c|c|}
\hline Location & Sketch of tunnel face & & Over-limit times \\
\hline K16+935 926 & $\begin{array}{l}\text { Contour line of collapse } \\
\text { Contstone line of excavation medium grain } \\
\text { in the thick coal seam }\end{array}$ & $\begin{array}{l}\text { ne of } \\
\text { d cavity } \\
\text { on } \\
\text { rbonaceous mudstone } \\
\text { mall amount of thin } \\
\text { acksand } \\
\text { flow }\end{array}$ & 25 \\
\hline K16+925 916 & $\begin{array}{l}\text { Fracture2 } \\
\text { Contour line of excavation } \\
\text { Sandstone with medium } \\
\text { grain in the thick } \\
\text { coal seam } \\
\text { Fracture }\end{array}$ & $\begin{array}{l}\text { ow } \\
\text { Grey carbonaceous } \\
\text { mudstone and a } \\
\text { small amount of } \\
\text { thin layer } \\
\text { packsand } \\
317^{\circ} \angle 59^{\circ}\end{array}$ & 6 \\
\hline
\end{tabular}




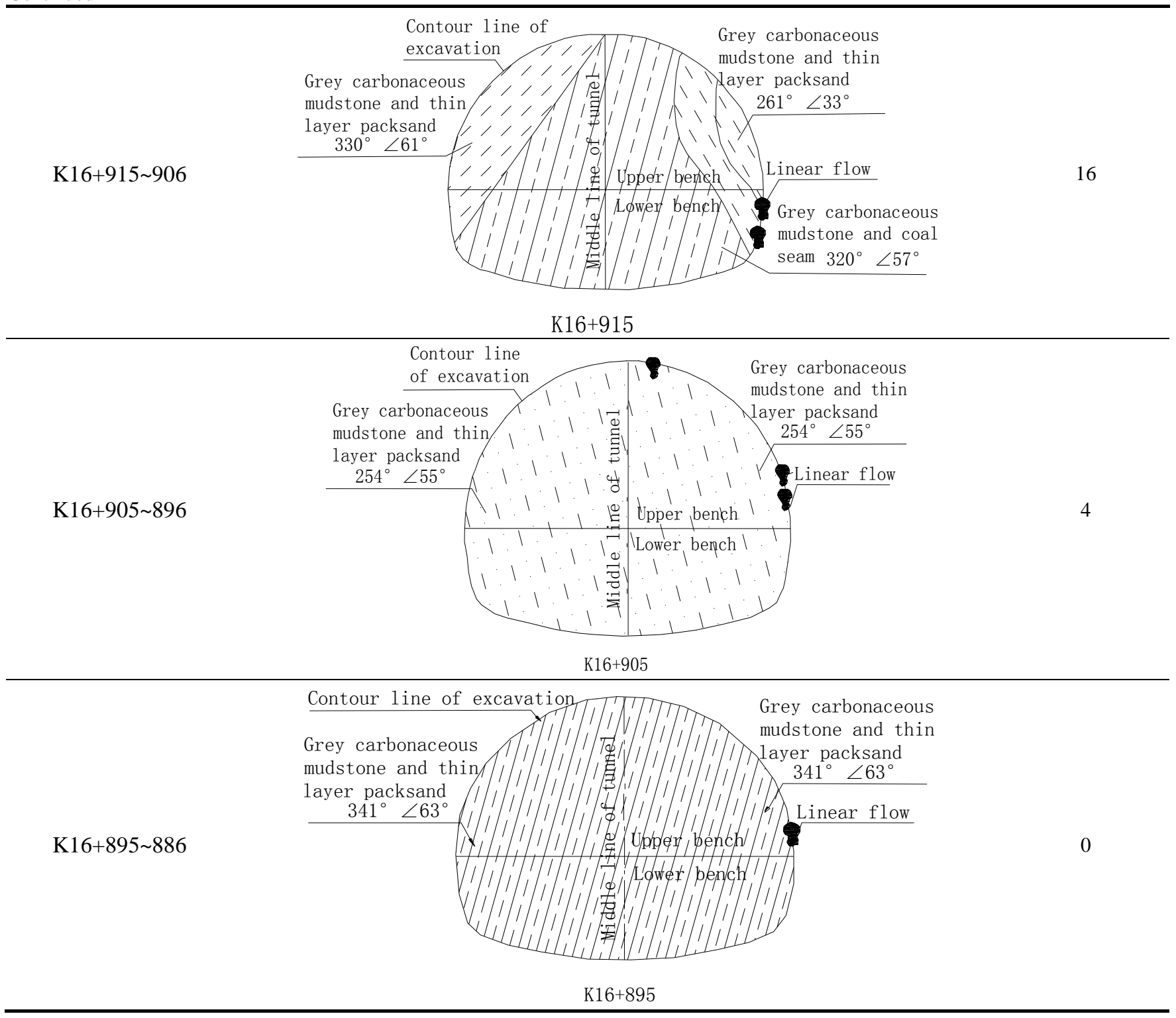

\section{Trend Prediction Model based on Fuzzy Pattern Recognition}

Pattern recognition refers to the processing and analysis of the various forms of information (numerical, literal and logical) to represent things or phenomena, and the process of description, identification, classification and interpretation of things or phenomena. Fuzzy pattern recognition technology is the application of fuzzy technology to the field of pattern recognition. The theory is based on fuzzy mathematics, and the model is described by a set of modules. The fuzzy set is divided into several subsets by membership degree, $m$ class has $m$ subsets. Then the subsets can be classified according to the principle of maximum membership or selection. This method mainly adopts the membership degree, fuzzy operation rules and fuzzy relation. It is used to measure the degree of similarity between samples and models, which reflect the main characteristics, with a considerable degree of interference and distortion. Because of the fuzziness of the identified object in the pattern recognition of abnormal gas (Pandite and Wu 1988, Li and Luo 2002, Shu et al 2004), the method of fuzzy pattern recognition was adopted in this paper.

\subsection{Fuzzy pattern recognition method}

\subsubsection{Feature extraction}

According to the characteristics of the class for recognition and the analysis the gas concentration curve, the following three features are extracted (Table 3): 1) Gas concentration value $F_{l}$. It is the amplitude of the curve, which can be described as "low" $\mu_{11}$, "medium" $\mu_{12}$ and "high" $\mu_{13}$; 2) $F_{2}$, the increment of a-b segment in Table 3III, which can be described as: "decline" $\mu_{21}$, "flat" $\mu_{22}$ and "rise"; 3) The peak number $F_{3}$, the number of peaks in the curve, and $\mu_{23}$ can be described as "no peak" $\mu_{31}$, "single peak" $\mu_{32}$, and "multi-peak" $\mu_{33}$. 


\subsubsection{Fuzzification of feature parameters}

Firstly, the original data is converted to feature vector based on the principle of the above feature extraction. Then, the feature vectors are classified according to the experiment and experience, and the membership degree $\mu_{i j}(I=1,2,3 ; j$ $=1,2,3$ ) of each parameter is determined (Zhao et al 2005). The principle of membership degree of each feature parameter is shown in Table 5.

Table 5 The principle of membership degree of each feature parameter

\begin{tabular}{cccc}
\hline $\boldsymbol{F}_{\mathbf{1}} / \boldsymbol{F}_{\mathbf{2}} / \boldsymbol{F}_{\mathbf{3}}$ & $\mu_{11} / \mu_{21} / \mu_{31}$ & $\mu_{12} / \mu_{22} / \mu_{32}$ & $\mu_{13} / \mu_{23} / \mu_{33}$ \\
\hline$F_{1} \geq 0.5 \% / F_{2} \geq 0.3 \% / F_{3}=0$ & $0 / 0 / 1$ & $0 / 0 / 0$ & $1 / 1 / 0$ \\
\hline $0.3 \% \leq F_{1}<0.5 \% / 0.1 \% \leq F_{2}<0.3 \% / F_{3}=1$ & $0 / 0 / 0$ & $0.25 / 0.25 / 1$ & $0.75 / 0.75 / 0$ \\
\hline $0.1 \% \leq F_{1}<0.3 \% / 0 \leq F_{2}<0.1 \% / F_{3}>1$ & $0 / 0 / 0$ & $0.75 / 1 / 0$ & $0.25 / 0 / 1$ \\
\hline$F_{1}<0.1 \% / F_{2}<0$ & $1 / 1 /$ & $0 / 0 /$ & $0 / 0 /$ \\
\hline
\end{tabular}

The combination of membership functions $\mu_{i j}$ of $F_{i}$ was used to express fuzzy sets $A_{i}$ of various typical anomalies, $A_{i}=\left(\mu_{11}, \mu_{12}, \mu_{13}, \mu_{21}, \mu_{22}, \mu_{23}, \mu_{31}, \mu_{32}, \mu_{33}\right)$, and each kind of typical abnormal waveforms is fuzzy subset of $A_{i}$, which is expressed as follows:

Flat type normality: $A_{l}=(1,0,0 ; 0,1,0 ; 1,0,0)$

Triangular type normality: $A_{l l}=(1,0.5,0.5 ; 0,1,0 ; 0,1,0)$

Increment type normality: $A_{31}=(0,1,0 ; 0,1,0 ; 0,1,0)$

Increment type abnormality: $A_{32}=(0,1,0 ; 0,1,0 ; 1,0,0)$

Multi-peak type abnormality: $A_{2}=(0,0.5,0.5 ; 0,0.5,0.5 ; 0$, $0,1)$

In this paper, the membership degree partition principle and fuzzy sets of various typical anomalies were obtained from the in-situ investigation and experience judgment of Zipingpu tunnel.

\subsubsection{Evaluation criterion}

Euclidean distance is a classically used means to measure the distance between two vectors. In this work, it is chosen as the judgment criterion of the closeness degree on the sample training set, and the formula is as follows:

$$
\rho(\underset{\sim}{\boldsymbol{A}}, \underset{\sim}{\boldsymbol{B}})=1-\frac{1}{\sqrt{n}} \sqrt{\sum_{i=1}^{n}\left(\mu_{A}\left(x_{i}\right)-\mu_{B}\left(x_{i}\right)\right)^{2}}
$$

where $A \& B$ are fuzzy sets, $n$ is the element numbers, $\mu_{A}\left(x_{i}\right)$ and $\mu_{B}\left(x_{i}\right)$ are membership functions.

\subsection{Pattern recognition of the Zipingpu tunnel gas monitoring data}

The monitoring data from three actual locations in Zipingpu tunnel was selected as research examples (Figs. 4 to 6): 1) Gas monitoring data of probe $01 \mathrm{~A} 01$, hourly monitoring data in seven days (from Nov 20 to 26, 2007); 2) Gas monitoring data of the left arch foot in the place $\mathrm{k} 16+650$, 30 times in four days (from Dec 7 to 10, 2007); and 3) The daily average monitoring data in the place K16+993 (from Nov 19 to Dec 13, 2005). Fuzzy pattern recognition method is used to predict the trend.

The data in green color is used for modeling, and the data in red color is used to test the accuracy of the prediction model. The feature vector of the sample tested is as follows:

$$
\begin{aligned}
& \left\{F_{1}, F_{2}, F_{3}\right\}=\{0.08,0.06,0\} \\
& \left\{F_{1}, F_{2}, F_{3}\right\}=\{0.55,0.52,1\} \\
& \left\{F_{1}, F_{2}, F_{3}\right\}=\{0.09,0.06,2\}
\end{aligned}
$$

According to the division principle of membership degree in Table 5, $F_{i}$ was transformed into the feature vector in the domain as shown in Table 6 . The closeness degree was calculated using the Euclid distance closeness degree formula $\mathrm{Eq}(1)$, as shown in Table 7.

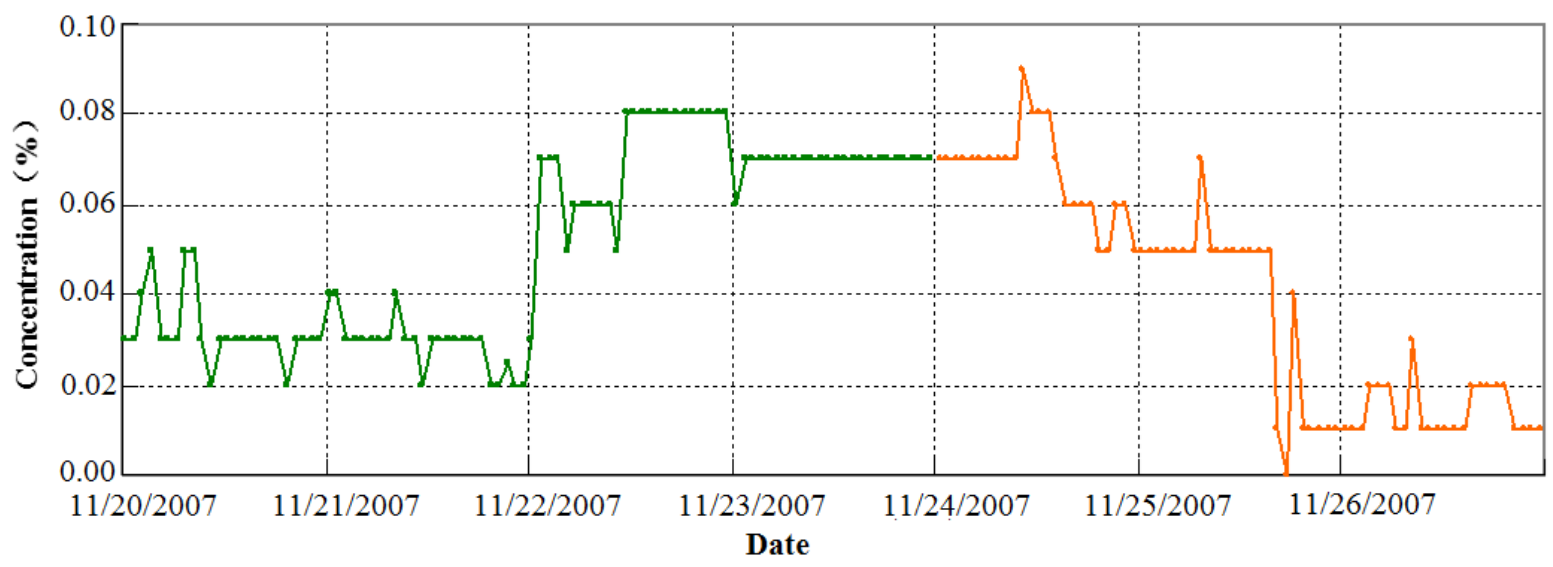

Fig. 4 Gas monitoring data of probe $01 \mathrm{~A} 01$ at the tunnel face in the place K16+650 


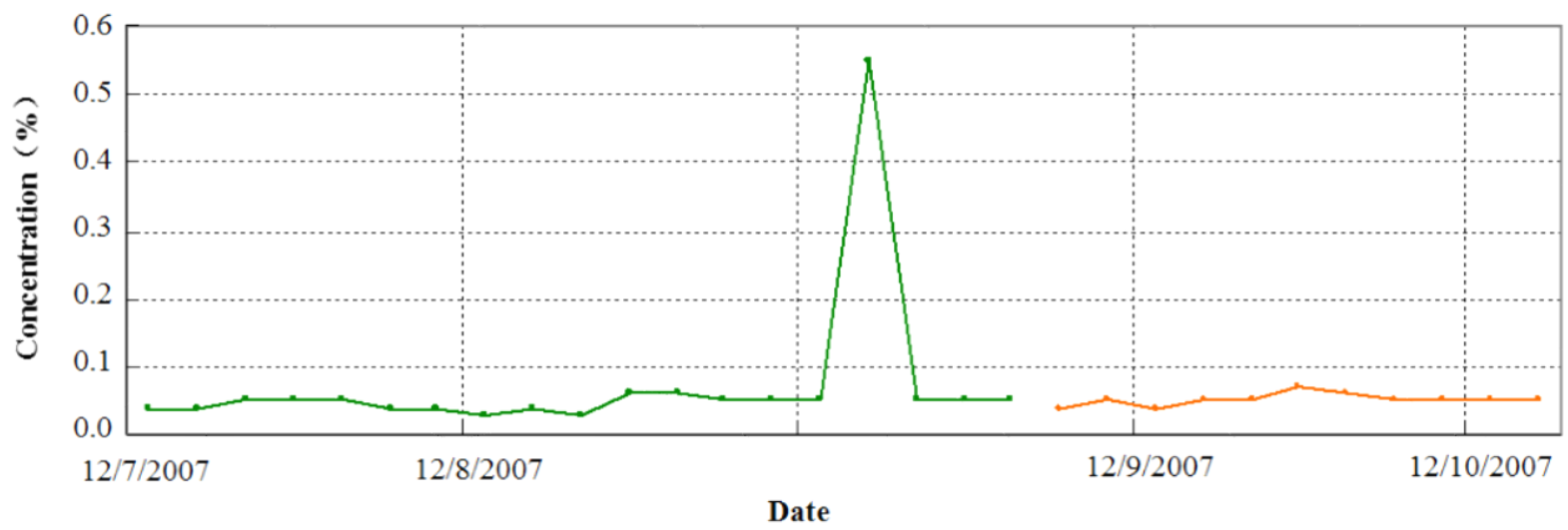

Fig. 5 Gas monitoring data at the left foot of arch in the place K16+650

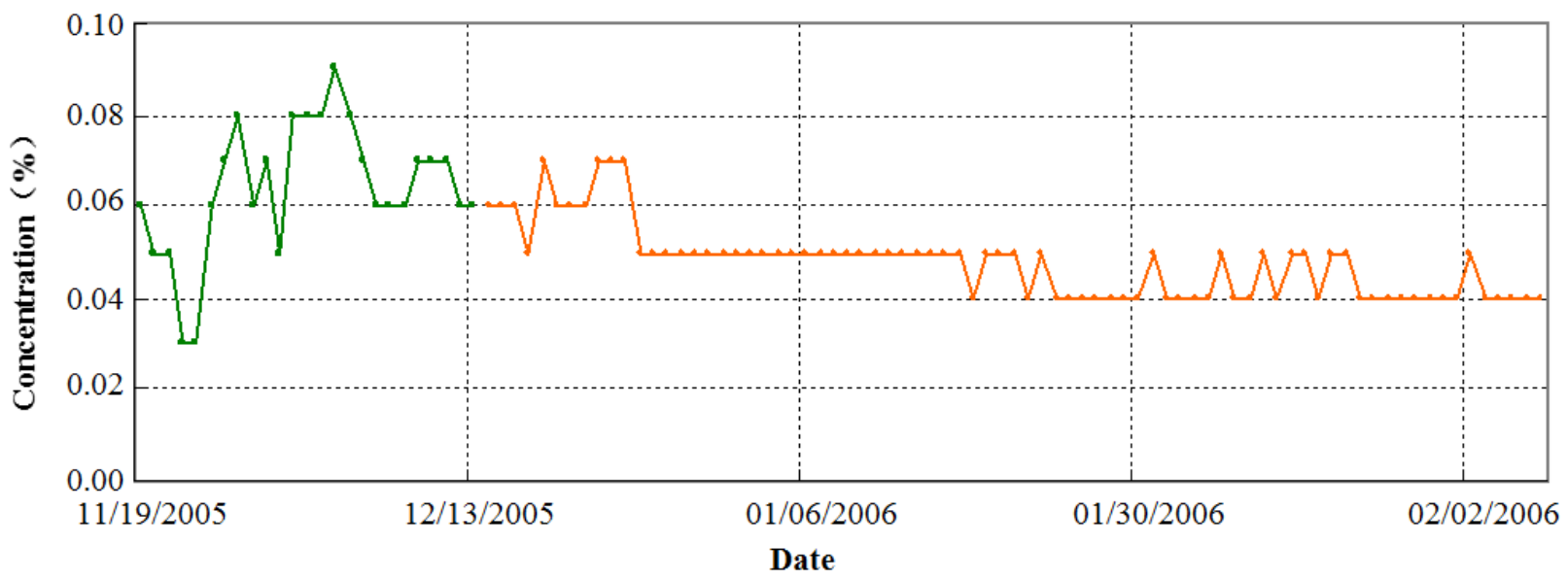

Fig. 6 Gas monitoring data at the tunnel face in the place K16+993

Table 6 Pattern sample set tested

\begin{tabular}{cccccccccc}
\hline$\mu_{i j}$ & $\mu_{11}$ & $\mu_{12}$ & $\mu_{13}$ & $\mu_{21}$ & $\mu_{22}$ & $\mu_{22}$ & $\mu_{31}$ & $\mu_{32}$ & $\mu_{33}$ \\
\hline$B_{1}$ & 1 & 0 & 0 & 0 & 1 & 0 & 1 & 0 & 0 \\
\hline$B_{2}$ & 0 & 0 & 1 & 0 & 0 & 1 & 0 & 1 & 0 \\
\hline$B_{3}$ & 1 & 0 & 0 & 0 & 1 & 0 & 0 & 0 & 1 \\
\hline
\end{tabular}

Table 7 Results of Euclid distance closeness degree

\begin{tabular}{cccccc}
\hline$\rho_{i}$ & $\rho\left(A_{1}, B_{1}\right)$ & $\rho\left(A_{11}, B_{1}\right)$ & $\rho\left(A_{31}, B_{1}\right)$ & $\rho\left(A_{32}, B_{1}\right)$ & $\rho\left(A_{2}, B_{1}\right)$ \\
\hline$B_{1}$ & 1 & 0.376 & 0.333 & 0.528 & 0.333 \\
\hline$\rho_{i}$ & $\rho\left(A_{1}, B_{2}\right)$ & $\rho\left(A_{11}, B_{2}\right)$ & $\rho\left(A_{31}, B_{2}\right)$ & $\rho\left(A_{32}, B_{2}\right)$ & $\rho\left(A_{2}, B_{2}\right)$ \\
\hline$B_{2}$ & 0.1835 & 0.473 & 0.333 & 0.423 & 0.451 \\
\hline$\rho_{i}$ & $\rho\left(A_{1}, B_{3}\right)$ & $\rho\left(A_{11}, B_{3}\right)$ & $\rho\left(A_{31}, B_{3}\right)$ & $\rho\left(A_{32}, B_{3}\right)$ & $\rho\left(A_{2}, B_{3}\right)$ \\
\hline$B_{3}$ & 0.528 & 0.376 & 0.333 & 0.333 & 0.514 \\
\hline
\end{tabular}

The type of $B_{1}, B_{2}$, and $B_{3}$ is determined according to closest principle. In Table 7 , the values of $\rho\left(A_{1}, B_{i}\right), \rho\left(A_{1 l}\right.$, $\left.B_{i}\right), \rho\left(A_{31}, B_{i}\right), \rho\left(A_{32}, B_{i}\right)$ and $\rho\left(A_{l}, B_{i}\right)$ are compared and the maximum value (marked in red color) is picked out. This indicates that the type of $B_{i}$ is closest to that of $A_{i}$ which corresponds to this maximum value. The prediction results based on the data curve in green color indicate that the gas concentration variation in the three actual monitoring 
locations is flat type normality, triangular type normality, and flat type normality, respectively. They are consistent with measured data (data curve in red color in Figs. 4 6).

\section{Conclusions}

Based on the special geological conditions of Zipingpu tunnel and the existing gas tunnel construction experiences, a real-time and continuous monitoring technique which combined automatic monitoring and manual test was built and employed to monitor gas concentration during construction. The basic forms of monitoring data have three types: triangle, multi-peak and increment from the characteristic analysis of a large amount of gas monitoring data. The major factors influencing the gas concentration are blasting, ventilation condition and geological structure. According to the monitoring data, a trend prediction model based on fuzzy pattern recognition is proposed. The practical application of this model in the construction of Zipingpu tunnel proved it can provide a good guidance for dynamic design and construction of this tunnel. This work may have a prospective application in some other complex gas tunnel projects.

\section{Acknowledgement}

We would like to acknowledge the support by the National Natural Science Foundation of China (Grant No. 41302244). We also would like to express appreciation to the reviewers and editors for their valuable comments and suggestions that helped to improve the quality of the paper.

\section{References}

Cao, L.M. and H. Wang, 2013. Prevention in construction of Wushaoling tunnel gas disaster and countermeasures. Inner Mongolia. Science Technology \& Economy, 10: $92-93$.

Chang, X.W., G.N. Wang and Y.P. Liu, 2013. Research on gas characteristics and partition prediction of gas of Laoshishan tunnel. J Railway Eng Soc, 4: 79 - 84.

Doyle, B.R., 1976. Hazardous Gases Underground, Applications to Tunnel Engineering. Marcel Dekker, New York.

Doyle, B.R., 2001. Hazardous Gasses Underground. Marcel Dekker, New York, 375pp.

Gan, G.Y., 2014. The geological characteristics of the storage status of the oil and gas along the ChengduChongqing passenger railway and comprehensive evaluation on the tunnel gas hazards. Master Degree Thesis. Southwest Jiaotong University, Chengdu.

Hu, C.T., 2012. Discussion of coal seam uncovering and outburst prevention technology for high gas working area of Sanlian tunnel. Engineering Construction, 2: 56 59.

Kang, X.B. and M. Xu, 2011. Description of gas tunnel construction today in China. Yangtze River, 42(3): 30 33.

Kang, X.B., M. Xu, S. Luo and Q. Xia, 2013. Study on formation mechanism of gas tunnel in non-coal strata. Natural Hazards, 66: 291 - 301. DOI: 10.1007/s11069012-0484-y.

Kang, X.B., S. Luo, Q.S. Li, M. Xu and Q. Li, 2017. Developing a risk assessment system for gas tunnel disasters in China. Journal of Mountain Science, 14(9): 1751 - 1762. DOI: 10.1007/s11629-016-3976-5.

Li, L.M. and S.X. Luo, 2002. Signal and System Analysis. University of Electronic Science and Technology of China Press.

Liu, Y.C. and G.L. Xing, 1999. A discussion on classification of mine gas. Mine Safety, 8: 22 - 26.

Liu, Z.D. and Y.S. Zhao, 2007. Trend prediction technology of coal mine gas monitoring system. Coal Mine Safety, 38(3): 57 - 59.

State Administration of Work Safety and State Administration of Coal Mine Safety, 2016. Coal Mine Safety Regulations. Beijing: China Coal Industry Publishing House.

Professional Standards of the People's Republic of China, 2003. Technical Code for Railway Tunnel with Gas (TB10120-2002). Beijing: China Railway Publishing House.

Pandite, S.M. and X.M. Wu, 1988. Time Series and System Analysis and Application. Machinery Industry Press.

Shu, N., H.C. Ma and H.L. Sun, 2004. Pattern Recognition Theory and Methods, Wuhan University Press.

Su, P.D., Z.B. Li and X.L. Fan, 2011. Prediction and study of shallow reservoired natural gas in Meilingguan tunnel of Lanzhou-Chongqing Railway. Subgrade Engineering, 1: 28 - 30.

Tang, Y.Q., W.M. Ye and H. Yu, 2003. Marsh gas in shallow soils and safety measures for tunnel construction. Eng Geol, 67: 373 - 378.

Yuan, H., 2014. Research on gas occurrence and migration in tunnel of Cheng-de-nan express way. Master Degree Thesis. Southwest Jiaotong University, Chengdu.

Zhao, H.Y., G.Q. Zheng and J.J. Bao, 2005. Fuzzy Mode Identification for Car Identifuing. Tractor \& Farm Transporter, 2: 27 - 29.

Zhong, Z.Y., 2006. Research on ventilation \& gas intensive monitoring system for small coal mine. PhD Dissertation. China University of Geosciences, Wuhan. 